\title{
Selección de contratistas y adjudicación de contratos (con especial referencia a la Administración Local)*
}

\author{
Martín M. ${ }^{a}$ Razquín Lizarraga \\ Catedrático de Derecho Administrativo. Universidad Pública de Navarra.
}

Sumario: 1. LA REGULACIÓN DE LA LCSP: MARCO GENERAL, NOVEDADES ESTRUCTURALES Y ADMINISTRACIÓN LOCAL. - 2. LOS PRINCIPIOS DE LAADJUDICACIÓN DE CONTRATOS.-3. LOS TIPOS DE ENTES DEL SECTOR PÚBLICO Y LA ADJUDICACIÓN DE CONTRATOS. 3.1. Los tres niveles de aplicación de la LCSP. 3.2. Aplicación total de la LCSP a los contratos de las Administraciones Públicas. 3.3. Aplicación parcial o mínima de la LCSP a los contratos de los entes del sector público que son poderes adjudicadores pero no Administraciones Públicas. 3.3.1. Aplicación parcial a los contratos sujetos a regulación armonizada. 3.3.2. Aplicación mínima a los contratos no sujetos a regulación armonizada. 3.4. Aplicación mínima de la LCSP a los contratos de los demás entes del sector público que no sean poderes adjudicadores. - 4. LA TRAMITACIÓN DE LOS PROCEDIMIENTOS DE ADJUDICACIÓN. 4.1. Fase previa: órgano competente para contratar, preparación del contrato y la aprobación del expediente de contratación. 4.2. Convocatoria de la licitación. 4.3. Plazos de presentación de proposiciones o de solicitudes de participación. 4.4. Proposiciones de los interesados. 4.5. La posibilidad de subasta electrónica. 4.6. Los criterios de selección del adjudicatario. 4.7. La adjudicación de los contratos: provisional y definitiva. 4.8. Notificación y publicidad de las adjudicaciones. 4.9. Formalización del contrato. -5. LOS DIFERENTES PROCEDIMIENTOS DE ADJUDICACIÓN. 5.1. Los procedimientos simplificados de adjudicación. 5.1.1. Los contratos menores. 5.1.2. El procedimiento negociado sin publicidad. 5.2. Los procedimientos no simplificados. 5.2.1. El procedimiento negociado con publicidad. 5.2.2. El procedimiento abierto. 5.2.3. El procedimiento restringido. 5.3. El procedimiento complejo: el diálogo competitivo. 5.3.1. Supuestos de diálogo competitivo. 5.3.2. Tramitación. 5.4 El procedimiento especial: los concursos de proyectos.-6. OTROS MODOS O PROCEDIMIENTOS DE ADJUDICACIÓN DE LAS ADMINISTRACIONES PÚBLICAS. 6.1. Acuerdos marco. 6.2. Sistemas dinámicos de contratación. 6.3. Centrales de contratación. 6.4. Las Juntas de Contratación.

\footnotetext{
* Este estudio tiene su origen en la Ponencia desarrollada en el marco de la Jornada sobre «El nuevo marco de la contratación pública y su incidencia en la Administración Local», organizada por la Federación de Municipios de Cataluña y celebrada en Barcelona el día 7 de mayo de 2008.
} 


\section{LA REGULACIÓN DE LA LCSP: MARCO GENERAL, NOVEDADES ESTRUCTURALES Y ADMINISTRACIÓN LOCAL}

La LCSP ${ }^{1}$ se separa de la arquitectura adoptada por el TRLCAP y dedica su Libro III a la «Selección del contratista y adjudicación de contratos». Este Libro III se divide en dos Títulos, el Título I sobre «Adjudicación de los contratos», subdividido a su vez en dos Capítulos, sobre los contratos de las Administraciones Públicas y sobre los contratos de los demás entes del sector público, y el Título II sobre «Racionalización técnica de la contratación» referido a otras modalidades de contratación a las que también pueden acudir las Administraciones Públicas.

Esta regulación es consecuencia del nuevo enfoque que adopta la LCSP referido a los contratos de todos los entes del sector público, perspectiva que no debe provocar engaño en el jurista puesto que, como se verá más adelante, la LCSP establece en este Libro III disposiciones limitativas de alcance sólo para los contratos de las Administraciones Públicas (con independencia de que sean contratos administrativos o privados, como establecen los arts. 19.2 y 20.2 LCSP) y para los contratos sujetos a regulación armonizada (art. 13 LCSP), dejando los restantes contratos sujetos solamente a reglas mínimas más bien principiales.

La exposición de motivos de la LCSP destaca algunas de las novedades que se introducen: «Obligadamente, la nueva Ley viene también a efectuar una revisión general de la regulación de la gestión contractual, a fin de avanzar en su simplificación y racionalización, y disminuir los costes y cargas que recaen sobre la entidad contratante y los contratistas particulares. Esta revisión ha afectado, de forma particular, al sistema de clasificación de contratistas, a los medios de acreditación de los requisitos de aptitud exigidos para contratar con el sector público, y a los procedimientos de adjudicación, elevando las cuantías que marcan los límites superiores de los simplificados — procedimiento negociado y el correspondiente a los contratos menores - y articulando un nuevo procedimiento negociado con publicidad para contratos no sujetos a regulación armonizada que no superen una determinada cuantía. Además, y desde un punto de vista

1 Las abreviaturas que se utilizan en el presente trabajo son las siguientes:

- LCSP: Ley 30/2007, de 30 de octubre, de Contratos del Sector Público.

- TRLCAP: Texto Refundido de la Ley de Contratos de las Administraciones Públicas de 2000.

- RGLCAP: Reglamento General de la Ley de Contratos de las Administraciones Públicas de 2001.

- LRBRL: Ley reguladora de las Bases de Régimen Local de 1985.

- TRRL: Texto Refundido de las disposiciones legales vigentes en materia de régimen local de 1986.

- TJCE: Tribunal de Justicia de las Comunidades Europeas.

- LRJPAC: Ley de Régimen Jurídico de las Administraciones Públicas y del Procedimiento Administrativo Común. 
SELECCIÓN DE CONTRATISTAS Y ADJUDICACIÓN DE CONTRATOS...

formal, se ha aprovechado para incorporar a nuestra legislación la terminología comunitaria de la contratación, con el fin de facilitar, ya desde el plano semántico, la interoperabilidad con los sistemas europeos de contratación. Esto ha supuesto el abandono de ciertas denominaciones tradicionales en nuestro derecho, que no de los correspondientes conceptos, que subsisten bajo nombres más ajustados al contexto europeo. En particular, los términos «concurso» y «subasta» - que en la legislación nacional se referían, de forma un tanto artificiosa, a «formas de adjudicación» del contrato como instrumento que debía utilizarse en conjunción con los «procedimientos de adjudicación», se subsumen en la expresión «oferta económicamente más ventajosa» que remite en definitiva, a los criterios que el órgano de contratación ha de tener en cuenta para valorar las ofertas de los licitadores en los diferentes procedimientos abiertos, restringidos o negociados, y ya se utilice un único criterio (el precio, como en la antigua «subasta») o ya se considere una multiplicidad de ellos (como en el antiguo «concurso») - . El concepto legal de «oferta económicamente más ventajosa» es, sin embargo, más amplio que el manejado en la Directiva 2004/18, englobando tanto la noción estricta presente en la norma comunitaria - que presupone la utilización de una multiplicidad de parámetros de valoración-, como el criterio del «precio más bajo», que dicha disposición distingue formalmente de la anterior; la Ley ha puesto ambos conceptos comunitarios bajo una misma rúbrica para evitar forzar el valor lingüístico usual de las expresiones utilizadas (no se entendería que la oferta más barata, cuando el único criterio a valorar sea el precio, no fuese calificada como la «económicamente más ventajosa»), y para facilitar su empleo como directriz que resalte la necesidad de atender a criterios de eficiencia en la contratación» (apartado IV. 4).

De la lectura del texto transcrito cabe observar que las modificaciones que se introducen en el Libro II no son de gran calado, puesto que constituyen más bien una nueva adaptación del Derecho comunitario, ahora de la Directiva 2004/18/CE, al ordenamiento jurídico español o persiguen ofrecer una mayor simplificación en la gestión contractual arbitrando procedimientos más ágiles para los entes del sector público.

También la exposición de motivos de la LCSP destaca la incorporación de nuevos procedimientos de adjudicación: «.... a la articulación de un nuevo procedimiento de adjudicación, el diálogo competitivo, pensado para contratos de gran complejidad en los que la definición final de su objeto sólo puede obtenerse a través de la interacción entre el órgano de contratación y los licitadores; a la nueva regulación de diversas técnicas para racionalizar las adquisiciones de bienes y servicios (acuerdos marco, sistemas dinámicos de adquisición y centrales de compras)» (apartado IV.2).

Así pues, en cuanto a la transposición del Derecho comunitario en este ámbito de la adjudicación de contratos, se introduce el nuevo procedimiento del diálogo competitivo o se recurre a la utilización de la nueva terminología comunitaria sustitutiva del concurso o la subasta. 
Respecto de la simplificación, la LCSP tiene a ampliar los supuestos en que se puede acudir a los contratos menores o al procedimiento negociado (con o sin publicidad) y, asimismo, arbitra otros medios de racionalización de la contratación como son los acuerdos marco, los sistemas dinámicos de contratación y las centrales de contratación.

Consecuencia de esta simplificación es que la LCSP crea un escalonamiento de los contratos de las Administración Públicas (más que de los entes del sector público) con arreglo al principio general de exigencia de requisitos más estrictos en función de su cuantía: a menor cuantía, menores requisitos y a mayor cuantía, mayor procedimentalización, mayores requisitos y formalidades. Ello permite cifrar la existencia de cuatro niveles de contratación en las Administraciones Públicas:

a) Contratos menores.

b) Contratos no sujetos a regulación armonizada para los que se permite, en razón de su cuantía, la utilización del procedimiento negociado con o sin publicidad.

c) Contratos no sujetos a regulación armonizada para los que se exige su sometimiento a procedimientos más formalizados, fundamentalmente, abiertos y restringidos.

d) Contratos sujetos a regulación armonizada ${ }^{2}$ bien en razón de su cuantía (por superar el umbral comunitario) o bien por tratarse de contratos de colaboración del sector público y el sector privado. Se les somete a unos requisitos de publicidad específicos, dado que a éstos se les aplica la Directiva 2004/18/CE. Se utilizarán los procedimientos negociados con publicidad (excepcional), abiertos, restringidos y de diálogo competitivo.

Asimismo la LCSP señala que asume «las nuevas tendencias a favor de la desmaterialización de los procedimientos, optando por la plena inserción de los medios electrónicos, informáticos y telemáticos en el ámbito de la contratación pública, a fin de hacer más fluidas y transparentes las relaciones entre los órganos de contratación y los operadores económicos» (exposición de motivos apartado IV.3). La utilización de las nuevas tecnologías se halla presente a lo largo de las disposiciones del Libro III: publicidad en el perfil del contratante, subasta electrónica, sistemas dinámicos de contratación o comunicaciones e información por medios electrónicos a los contratistas.

La LCSP es aplicable, sin duda alguna, a la Administración Local. Esta aplicación se realiza desde dos vertientes:

2 Sólo respecto de estos contratos cabe afirmar con propiedad que la LCSP establece normas limitativas de los procedimientos de adjudicación tanto para las Administraciones Públicas como para aquellos otros entes del sector público que sean poderes adjudicadores pero no Administraciones Públicas. 
SELECCIÓN DE CONTRATISTAS Y ADJUDICACIÓN DE CONTRATOS...

a) Sujeción general: las entidades locales están sometidas a la LCSP y, por tanto, se encuentran dentro de su ámbito subjetivo de aplicación (art. 3 LCSP). Además la sujeción alcanza a:

1) A las entidades locales en cuanto Administraciones Públicas (entidades locales enumeradas en el art. 3 LRBRL).

2) A sus organismos públicos (organismos autónomos, entidades públicas empresariales $^{3}$ o cualesquiera otros entes de derecho público vinculados a una entidad local).

3) A las sociedades mercantiles o fundaciones en que la participación de las entidades locales o de sus organismos públicos supere el 50 por ciento del capital social o del total de la aportación constitutiva o del patrimonio fundacional ${ }^{4}$.

4) A los consorcios constituidos conforme a la legislación local.

5) A cualesquiera otros entes del ámbito local que encajen dentro del concepto de la Directiva 2004/18/CE de «organismo de derecho público», que ahora recoge la letra h) del art. 3.1 LCSP.

6) A las asociaciones constituidas por cualesquiera de los entes anteriores.

b) Normas específicas: La LCSP establece normas específicas referidas a las entidades del ámbito local. La LCSP recoge una regulación específica referida a las entidades locales para lo que efectúa dos tipos de operaciones:

1) Establecimiento de normas específicas: la LCSP, siguiendo la estela de

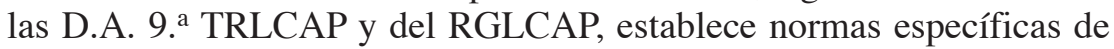
contratación para las entidades locales en su D.A. 2. ${ }^{\text {a5 }}$.

2) Derogación o modificación de normas de la LRBRL: la LCSP deroga la regulación de la LRBRL sobre contratación (competencias y aspectos sustantivos) así como también del TRRL ${ }^{6}$ (D. Derogatoria única letras b)

\footnotetext{
3 No obstante, los organismos dependientes de las entidades locales asimilados a entidades públicas empresariales no tendrán la consideración de Administraciones Públicas (art. 3.2 párrafo último LCSP).

4 Téngase en cuenta lo dispuesto en el art. 85.2 LRBRL sobre los modos de gestión de los servicios públicos, ahora modificado por la LCSP en su D. F. 1. ${ }^{\text {a }}$, y en el art. 8.2 LCSP respecto de los contratos de gestión de servicios públicos.

5 Vid. R. J. ORTEGa MonTORO, «La contratación de las Entidades Locales en la nueva Ley de Contratos del Sector Público 30/2007, de 30 de octubre: Sus especialidades», en EL CONSULTOR, núm. 1, 15 enero 2008, en especial, pp. 30-42 en que analiza esta D. A. 2. ${ }^{\text {a }}$ LCSP.

6 Del TRRL se dejan en vigor solamente tres preceptos, los arts. 111, 114 y 117, que, a mi juicio, debieron haber sido derogados por la LCSP (para culminar su posición «integradora»), puesto que el principio de libertad de pactos del art. 111 TRRL se encuentra recogido en el art. 25 LCSP, las prerrogativas de los entes locales del art. 114 TRRL están relacionadas en el art. 194 LCSP fijándose además un procedimiento para su
} 
y c) LCSP). Así también la LCSP modifica el art. 85.2 LRBRL sobre los modos de gestión de los servicios públicos locales (D. F. 1. ${ }^{\mathrm{a}}$ LCSP).

\section{LOS PRINCIPIOS DE LA ADJUDICACIÓN DE CONTRATOS}

La LCSP establece diversos principios básicos aplicables a todos los procedimientos de adjudicación de los contratos celebrados por todos los entes del sector público.

El Derecho comunitario exige la aplicación de los principios del Derecho comunitario originario a todo tipo de contratos públicos y con independencia de que superen o no el umbral comunitario ${ }^{7}$. Por ello estos principios se aplican a todos los contratos del sector público y su violación constituye un incumplimiento del Derecho comunitario que puede ser objeto de control por el Tribunal de Justicia de las Comunidades Europeas. Así el TJCE ha declarado que los principios del Derecho comunitario originario son aplicables:

a) A los contratos excluidos de la Directiva 2004/18/CE como son las concesiones de servicios. Es el caso de la Sentencia de 13 de abril de 2005 (C-458/03), Parking Brixen ${ }^{8}$, cuya doctrina se reitera en las Sentencias de 6 de abril de 2006 (C-410/04) y de 13 de septiembre de 2007 (C-260/04).

ejercicio en el art. 195 LCSP y, por último, el art. 117 LCSP sobre contratación de emergencia debe entenderse sustituido por lo dispuesto en el art. 97 LCSP sobre tramitación de emergencia, máxime cuando estos preceptos de la LCSP son en su totalidad o en su mayor parte (excepto las referencias a la Administración del Estado) de carácter básico.

7 Es ilustrativo al efecto el apartado 2 de la exposición de motivos de la Directiva 2004/18/CE: «La adjudicación de contratos celebrados en los Estados miembros por cuenta de autoridades estatales, regionales o locales y otros organismos de derecho público está supeditada al acatamiento de los principios del Tratado y, en particular, los principios de la libre circulación de mercancías, la libertad de establecimiento y la libre prestación de servicios, así como de los principios que de estas libertades se derivan, como son el principio de igualdad de trato, el principio de no discriminación, el principio de reconocimiento mutuo, el principio de proporcionalidad y el principio de transparencia. No obstante, para la adjudicación de contratos públicos por importes superiores a una determinada cantidad, es conveniente elaborar a escala comunitaria disposiciones de coordinación de los procedimientos nacionales de adjudicación que estén basadas en dichos principios, de forma que queden garantizados sus efectos, y abrir a la competencia la contratación pública. Por consiguiente, dichas disposiciones de coordinación deben interpretarse con arreglo a las normas y principios antes mencionados y a las demás normas del Tratado».

8 Así lo afirman los fundamentos jurídicos 46 a 50 de esta Sentencia:

«46 Pese a que, en el estado actual del Derecho comunitario, los contratos de concesión de servicios públicos se encuentran excluidos del ámbito de aplicación de la Directiva 92/50, las autoridades públicas que los celebren están obligadas no obstante a respetar, en general, las normas fundamentales del Tratado CE y, en especial, el principio de no discriminación por razón de la nacionalidad (véanse en este sentido las sentencias de 7 de diciembre de 2000, Teleaustria y Telefonadress, C-324/98, Rec. p. I-10745, apartado 60, y de 21 de julio de 2005, Coname, C-231/03, Rec. p. I-0000, apartado 16).

47 El artículo 12 CE proclama la prohibición de toda discriminación por razón de nacionalidad. Entre las disposiciones del Tratado aplicables más específicamente a las concesiones de servicios públicos cabe destacar, en particular, el artículo $43 \mathrm{CE}$, cuyo primer párrafo prohíbe las restricciones a la libertad 
b) Así también se aplica a los contratos incluidos en el ámbito de la Directiva (obras, concesión de obras públicas, suministro y servicios), pero que no se hallan sometidos a ella por no alcanzar el umbral comunitario al no superar una determinada cuantía. Así se declara en la Sentencia del TJCE de 14 de junio de $2007(\mathrm{C}-6 / 05)^{9}$.

\section{Los principios a que se refiere la LCSP son los tres siguientes:}

a) La igualdad: los órganos de contratación deben respetar el principio de igualdad, lo que significa que no pueden dar un trato discriminatorio a ningún empresario (art. $123 \operatorname{LCSP}^{10}$ ).

de establecimiento de los nacionales de un Estado miembro en el territorio de otro Estado miembro, y el artículo $49 \mathrm{CE}$, conforme a cuyo primer párrafo quedarán prohibidas las restricciones a la libre prestación de servicios dentro de la Comunidad para los nacionales de los Estados miembros establecidos en un país de la Comunidad que no sea el del destinatario de la prestación.

48 Según la jurisprudencia del Tribunal de Justicia, los artículos 43 CE y 49 CE constituyen una expresión particular del principio de igualdad de trato (véase la sentencia de 5 de diciembre de 1989, Comisión/ Italia, C-3/88, Rec. p. 4035, apartado 8). La prohibición de discriminación por razón de nacionalidad constituye igualmente una expresión específica del principio general de igualdad de trato (véase la sentencia de 8 de octubre 1980, Überschär, 810/79, Rec. p. 2747, apartado 16). En la jurisprudencia relativa a las directivas comunitarias en materia de contratación pública, el Tribunal de Justicia ha precisado que el principio de igualdad de trato de los licitadores tiene por objeto que todos los licitadores dispongan de las mismas oportunidades al formular el contenido de sus ofertas, con independencia de su nacionalidad (véase en este sentido la sentencia de 25 de abril de 1996, Comisión/Bélgica, C-87/94, Rec. p. I-2043, apartados 33 y 54). De ello se deduce que el principio de igualdad de trato de los licitadores es aplicable a las concesiones de servicios públicos aun cuando no exista una discriminación por razón de nacionalidad.

49 Los principios de igualdad de trato y de no discriminación por razón de nacionalidad implican, en particular, una obligación de transparencia que permita que la autoridad pública concedente se asegure de que los mencionados principios son respetados. Esta obligación de transparencia que recae sobre dicha autoridad consiste en garantizar, en beneficio de todo licitador potencial, una publicidad adecuada que permita abrir a la competencia la concesión de servicios y controlar la imparcialidad de los procedimientos de adjudicación (véase en este sentido la sentencia Teleaustria y Telefonadress, antes citada, apartados 61 y 62).

50 Corresponde a la autoridad pública concedente apreciar, bajo el control de los tribunales competentes, la adecuación de las modalidades de licitación a las particularidades de cada concesión de servicios públicos. Sin embargo, la falta total de licitación en la adjudicación de una concesión de servicios públicos como la que es objeto del caso de autos no responde a los requisitos de los artículos 43 CE y 49 CE ni a los principios de igualdad de trato, no discriminación y transparencia».

9 En el F.J. 33 de esta Sentencia se afirma lo siguiente: «Efectivamente, procede señalar que el órgano jurisdiccional remitente ha calificado al Venizeleio-Pananeio de «entidad adjudicadora». Esta calificación también la admite el Gobierno griego, el cual declaró en la vista que dicho hospital es un organismo de Derecho público asimilado al Estado. Ahora bien, en virtud de una reiterada jurisprudencia, aun cuando el valor de un contrato que sea objeto de una licitación no alcance el umbral de aplicación de las Directivas en las cuales el legislador comunitario haya regulado el ámbito de los contratos públicos y el contrato de que se trate no esté comprendido, por consiguiente, dentro del ámbito de aplicación de éstas últimas, sin embargo, las entidades contratantes que celebran un contrato están obligadas a respetar los principios generales del Derecho comunitario, tales como el principio de igualdad de trato y la obligación de transparencia que deriva de aquél (véanse, en este sentido, la sentencia de 7 de diciembre de 2000, Telaustria y Telefonadress, C-324/98, Rec. p. I-10745, apartados 60 y 61; auto Vestergaard, antes citado, apartados 20 y 21; sentencias de 21 de julio de 2005, Coname, C-231/03, Rec. p. I-7287, apartados 16 y 17, y de 13 de octubre de 2005, Parking Brixen, C-458/03, Rec. p. I-8585, apartados 46 a 48)».

10 Es transposición del art. 2 de la Directiva 2004/18/CE. 
b) La transparencia: los procedimientos de adjudicación deben ajustarse al principio de transparencia, que se encuentra en íntima vinculación con el anterior principio de igualdad de trato. ¿Cuál es su significado? Exige la publicidad del propio procedimiento, sea ésta del tipo que sea. Principalmente esta transparencia será efectiva mediante la publicidad (cuando así se exija y en los diversos medios en que se realice, fundamentalmente de forma general en el denominado perfil del contratante) y en los deberes de información que se recogen en diversas disposiciones de la LCSP ${ }^{11}$.

c) La confidencialidad: se recoge en el art. $124 \operatorname{LCSP}^{12}$ y se dirige a la prohibición de divulgación de información declarada confidencial, especialmente en relación con los secretos técnicos o comerciales y los aspectos confidenciales de las ofertas. Por eso se exige a los contratistas un deber de respeto de esta confidencialidad y, además, se fija un plazo mínimo de cinco años. Esta confidencialidad se recoge asimismo respecto de la información a facilitar en relación con la adjudicación de un contrato (art. 137.2 LCSP).

\section{LOS TIPOS DE ENTES DEL SECTOR PÚBLICO Y LA ADJUDICACIÓN DE CONTRATOS}

\subsection{Los tres niveles de aplicación de la LCSP}

La LCSP diferencia, en su ámbito de aplicación (art. 3), tres tipos de entes del sector público, lo que permite hablar, a los efectos de adjudicación de los contratos, de tres clases de contratos del sector público en función de las entidades del sector público que vayan a realizarlos, lo que determina una aplicación de la LCSP en grados bien diferentes. Son los tres siguientes:

1) Contratos de las Administraciones Públicas.

2) Contratos de los entes que son poderes adjudicadores pero no son Administraciones Públicas.

3) Contratos de otros entes y organismos integrados en el sector público pero que no son poderes adjudicadores ni Administraciones Públicas.

\footnotetext{
11 Un ejemplo de transparencia puede verse en el apartado 46 párrafo $2 .^{\circ}$ de la exposición de motivos de la Directiva 2004/18/CE: «A fin de garantizar la observancia del principio de igualdad de trato en la adjudicación de los contratos, conviene establecer la obligación - consagrada por la jurisprudencia - de asegurar la transparencia necesaria para que cualquier licitador pueda informarse razonablemente de los criterios y modalidades que se aplicarán para determinar la oferta económicamente más ventajosa».

Téngase en cuenta que la Sentencia del TJCE de 13 de octubre de 2005, Parking Brixen, se refiere de forma expresa a la obligación de transparencia en su F.J. 49, más arriba transcrito.

12 Se transpone lo dispuesto en el art. 6 de la Directiva 2004/18/CE.
} 
SELECCIÓN DE CONTRATISTAS Y ADJUDICACIÓN DE CONTRATOS...

\subsection{Aplicación total de la LCSP a los contratos de las Administraciones Públicas}

Las normas de la LCSP sobre selección y adjudicación de contratos se aplican tanto a los contratos administrativos como a los privados que celebren las Administraciones Públicas (arts. 19 y 20 LCSP).

Por tanto, el Capítulo I del Título I del Libro III de la LCSP («Selección del contratistas y adjudicación de los contratos) regula, en primer lugar, la adjudicación de contratos por las Administraciones Públicas y se refiere a todos los contratos que éstas celebren sin exclusión alguna.

\subsection{Aplicación parcial o mínima de la LCSP a los contratos de los entes del sector público que son poderes adjudicadores pero no Administraciones Públicas}

Para los poderes adjudicadores que no sean Administraciones Públicas, la Sección 1. a del Capítulo II del Libro III de la LCSP establece una serie de reglas de aplicación diferenciando entre contratos sujetos o no a regulación armonizada. Es evidente que la regulación viene justificada por la necesidad de someter los contratos sujetos a regulación armonizada a las disposiciones de la Directiva 2004/18/CE, mientras que en los demás la libertad del legislador español es total y, por tanto, se establecen muy escasas reglas más allá de las genéricas de respeto a los principios generales de la contratación de los entes públicos.

\subsubsection{Aplicación parcial a los contratos sujetos a regulación armonizada}

La regla general es la aplicación de las normas contenidas en el Capítulo I, antes expuestas, es decir, que estos poderes adjudicadores, a pesar de no ser Administraciones Públicas, deben acomodarse a las disposiciones establecidas para éstas en la LCSP (art. 174).

El art. 174 citado establece únicamente algunas salvedades a dicha regla general. Pueden distinguirse dos tipos de salvedades:

a) De carácter material o de fondo: se exceptúa la aplicación de diversas disposiciones generales. Así la letra a) del art. 174.1 dice así: «No serán de aplicación las normas establecidas en el segundo párrafo del apartado 2 del artículo 134 sobre intervención del comité de expertos para la valoración de criterios subjetivos, en los apartados 1 y 2 del artículo 136 sobre criterios para apreciar el carácter anormal o desproporcionado de las ofertas, en el artículo 140 sobre formalización de los contratos, en el artículo 144 sobre examen de las proposiciones y propuesta de adjudicación, y en el artículo 156 sobre los su- 
puestos en que es posible acudir a un procedimiento negociado para adjudicar contratos de gestión de servicios públicos». A ello debe añadirse el art. 174.2 relativo a la reducción de plazos en caso de urgencia.

b) De carácter formal o de publicidad: referidas a la publicación de anuncios en los diarios oficiales de ámbito estatal (BOE o Diarios Oficiales de la Comunidad Autónoma o Provincia). La letra b) del art. 174.1 señala: «No será preciso publicar las licitaciones y adjudicaciones en los diarios oficiales nacionales a que se refieren el párrafo primero del apartado 1 del artículo 126 y el párrafo primero del apartado 2 del artículo 138, entendiéndose que se satisface el principio de publicidad mediante la publicación efectuada en el «Diario Oficial de la Unión Europea» y la inserción de la correspondiente información en la plataforma de contratación a que se refiere el artículo 309 o en el sistema equivalente gestionado por la Administración Pública de la que dependa la entidad contratante, sin perjuicio de la utilización de medios adicionales con carácter voluntario».

\subsubsection{Aplicación mínima a los contratos no sujetos a regulación armonizada}

Por el contrario, respecto de estos contratos las reglas que se establecen son más bien mínimas y de carácter principial (art. 175), bastante similares por otra parte a las del artículo 176 relativo a los entes, organismos y entidades del sector público que no son poderes adjudicadores.

El art. 175 LCSP impone las siguientes tres reglas:

a) Sometimiento de la contratación a diversos principios: así se enumeran los principios de principios de publicidad, concurrencia, transparencia, confidencialidad, igualdad y no discriminación.

b) Sometimiento a instrucciones: estas instrucciones deben ser aprobadas por los órganos competentes de los propios entes. Las instrucciones deben ponerse a disposición de los interesados y publicarse en el perfil de contratante de la entidad.

c) Publicidad: se exige sólo para los contratos que superen los 50.000 euros y se limita a la publicación de información en el perfil de contratante de la entidad.

\subsection{Aplicación mínima de la LCSP a los contratos de los demás entes del sector público que no sean poderes adjudicadores}

Se establece una regulación bastante similar a la antes expuesta para los contratos no sujetos a regulación armonizada de los poderes adjudicadores 
que no son Administraciones Públicas. El art. 176 LCSP impone las siguientes reglas:

a) Sometimiento de la contratación a diversos principios: se reiteran los principios de publicidad, concurrencia, transparencia, confidencialidad, igualdad y no discriminación.

b) Criterio de adjudicación: debe ser el de la oferta económicamente más ventajosa o el del precio más bajo ${ }^{13}$.

c) Sometimiento a instrucciones: las instrucciones internas de contratación deben velar por el cumplimiento de los principios antes expuestos y del criterio de adjudicación. Asimismo estas instrucciones deben ponerse a disposición de los interesados y publicarse en el perfil de contratante de la entidad.

En definitiva, la adjudicación de los contratos que efectúen los entes del sector público local que sean poderes adjudicadores pero no Administraciones Públicas (salvo cuando se trate de contratos sujetos a regulación armonizada) o que no sean poderes adjudicadores queda excluida de la aplicación de las disposiciones generales para los contratos de las Administraciones Públicas que se van a exponer a continuación.

\section{LA TRAMITACIÓN DE LOS PROCEDIMIENTOS DE ADJUDICACIÓN}

El artículo 122.2 LCSP establece los procedimientos de adjudicación de los contratos de las Administraciones Públicas. Son los siguientes:

a) Procedimientos ordinarios: así se configuran el procedimiento abierto y el restringido.

b) Procedimientos extraordinarios o excepcionales: lo son el procedimiento negociado y el diálogo competitivo ${ }^{14}$, puesto que sólo puede acudirse a ellos en los casos expresamente previstos en la $\operatorname{LCSP}^{15}$.

c) Procedimiento especial: el previsto para el concurso de proyectos.

\footnotetext{
13 Entiendo que cabe utilizar cualquiera de los dos criterios de adjudicación, dada la redacción del art. 176.2 LCSP que se debe referir a lo dispuesto en el art. 134.1 LCSP. Cuando la LCSP quiere referirse solamente a un criterio de adjudicación, excluyendo el otro, así lo hace, como ocurre por ejemplo respecto del diálogo competitivo en el art. 167.2.

14 No obstante es el procedimiento obligado para los contratos de colaboración entre el sector público y el sector privado.

15 La doctrina insiste en su carácter excepcional (J. A. Moreno MolinA, en J. A. Moreno Molina y F. Pleite Guadamillas, La nueva Ley de Contratos del Sector Público. Estudio sistemático, Ed. La Ley, Madrid, 2007, págs. 471 y 480).
} 
La LCSP se ocupa, primero, de establecer los trámites comunes a todos los procedimientos de adjudicación, para después proceder a regular las especialidades de cada uno de ellos.

Procede, por tanto, examinar cada una de las fases de los procedimientos de adjudicación de forma diferenciada. Son las siguientes:

\subsection{Fase previa: órgano competente para contratar, preparación del contrato y la aprobación del expediente de contratación}

La D. A. 2. a , en sus apartados 1 y 2 , de la LCSP recoge las disposiciones sobre competencia para contratar en su división entre el Pleno y el Alcalde o Presidente de las entidades locales ya contenidas en los arts. 21 (letras ñ y p) y 22 (letras n y o) de la LRBRL para los municipios y en los arts. 33 (letras 1 y n) y 34 (letras k y m) para las Diputaciones provinciales, así como la competencia completa de la Junta de Gobierno Local en los municipios de gran población (art. 127.1.f) LRBRL). Estos preceptos de la LRBRL son derogados por la D. Derogatoria única letra b) de la LCSP. Así pues, la competencia se regirá por lo dispuesto en la LCSP, lo que motiva asimismo la derogación del art. 88 de la LRBRL.

Las novedades que se introducen son mínimas, excepto en dos aspectos:

a) El contrato de colaboración entre el sector público y el privado es siempre competencia del Pleno.

b) Introduce, dada su nueva redacción, algunos cambios respecto de las concesiones de bienes inmuebles (su importe se reduce ahora de 6 millones de euros a 3 , puesto que ingresan en el segundo párrafo de la D. A. 2. a y no en el primero) ${ }^{16}$.

El art. 94.1 LCSP establece que «completado el expediente de contratación, se dictará resolución motivada por el órgano de contratación aprobando el mismo y disponiendo la apertura del procedimiento de adjudicación».

Pues bien, la D.A. 2. ${ }^{\text {a }}$ LCSP, en su apartado 7, atribuye la aprobación del gasto y la apertura del procedimiento de adjudicación al órgano de contratación, que será el que corresponda según las reglas competenciales orgánicas antes expresadas. No obstante, en los municipios menores de 5.000 habitantes la aprobación del gasto puede ser sustituida por una certificación de existencia de crédito (apartado 6).

16 Las permutas quedan de nuevo en esta situación de división competencial, a pesar de que la Ley de Suelo 8/2007 había reformado el art. 22.2, letra o) a fin de incluir todas las permutas dentro de la competencia del Pleno. 
SELECCIÓN DE CONTRATISTAS Y ADJUDICACIÓN DE CONTRATOS...

\subsection{Convocatoria de la licitación}

La apertura del procedimiento de adjudicación se efectúa por medio de la convocatoria de licitación, prevista en el art. 126 LCSP. La publicidad constituye un factor esencial de la contratación, que viene además reforzado en la Directiva 2004/18/CE para los contratos a ella sujetos ${ }^{17}$.

Cabe diferenciar los siguientes supuestos de publicidad del anuncio de licitación:

a) Publicidad necesaria en Boletines Oficiales del Estado: se contempla una publicidad necesaria en el BOE, que puede ser sustituida por el BO de la Comunidad Autónoma o de la Provincia. En principio la publicidad del anuncio es de carácter obligado para todos los procedimientos de contratación, con excepción del procedimiento negociado (aunque sí es obligada en los supuestos del art. 161.1 y 2).

b) Publicidad necesaria en el DOUE ${ }^{18}$ : se exige para los contratos sujetos a regulación armonizada. En estos casos además deberán publicarse en el BOE.

c) Publicidad potestativa en el DOUE: permite la publicación en el DOUE de aquellos contratos de obras, suministros y servicios que no estén sujetos a regulación armonizada cuando así lo decidan los poderes adjudicadores.

d) Publicidad en el portal de la entidad contratante: se establece como una publicidad de carácter obligado y, además, añadida a las anteriores la publicación de los anuncios de licitación en el perfil del órgano de contratación. Sólo en el caso de los procedimientos negociados del art. 161.2 esta publicidad tendrá carácter sustitutivo de la publicación en los Diarios Oficiales.

Asimismo en los casos del art. 125 los órganos de contratación tienen la posibilidad de insertar un anuncio previo de las licitaciones que pretendan efectuar en los doce meses siguientes tanto en el DOUE o en su perfil de contratación. De esta publicación se deriva la permisión de una reducción en los plazos de presentación de proposiciones en los procedimientos abiertos y restringidos (art. 125.4 LCSP).

El contenido de los anuncios de licitación viene en gran parte predeterminado por los modelos establecidos tanto por el Derecho Comunitario como tam-

\footnotetext{
17 Así el art. 39 de la Ley catalana 3/2007, de 4 de julio, de la obra pública, titulado «publicidad y transparencia» insiste en este principio básico de la publicidad con especial referencia a la página web de la Generalidad, en definitiva, a lo que es el perfil del contratante previsto en el art. 42 de la LCSP.

18 Téngase en cuenta el Reglamento (CE) n. ${ }^{\circ}$ 1564/2005 de la Comisión, de 7 de septiembre de 2005, por el que se establecen los formularios normalizados para la publicación de anuncios en el marco de los procedimientos de adjudicación de contratos públicos con arreglo a las Directivas 2004/17/CE y 2004/18/CE del Parlamento Europeo y del Consejo, publicado en el DOUE n. ${ }^{\circ} 257$, de 1 de octubre de 2005.
} 
bién en el RGLCAP (art. 77), que dedica sus Anexos VII y VIII a estos modelos de anuncios de licitación en el BOE o en el DOUE. Además el art. 134.2 LCSP contempla como uno de los modos de publicidad previa de los criterios de adjudicación su inclusión en el anuncio de licitación.

\subsection{Plazos de presentación de proposiciones o de solicitudes de participación}

Comienzan a contar desde la publicación o la remisión del anuncio de publicación en el DOUE y deben hacer posible la presentación de proposiciones o solicitudes de participación. Se permite su reducción si la tramitación es urgente (art. 128 LCSP). Luego en relación con cada procedimiento concreto de adjudicación se establecen estos plazos: art. 143 para los procedimientos abiertos; art. 148 para las solicitudes de participación en los procedimientos restringidos y del diálogo competitivo - según el art. 165.2-; y art. 151 para las proposiciones.

\subsection{Proposiciones de los interesados}

El art. 129 LCSP regula las proposiciones de los interesados. Este precepto introduce muy pocas modificaciones, y ninguna de relieve, respecto de los arts. 79 y 80 del TRLCAP. Únicamente se observan dos novedades: la extensión de la prohibición de presentación de más de una proposición también respecto de las empresas vinculadas (apartado 4 del art. 129 LCSP) y la exigencia de que la proposición indique, de forma separada, el importe del IVA que debe ser repercutido.

La presentación de una proposición supone la aceptación incondicionada de todas las cláusulas o condiciones del contrato, «sin salvedad o reserva alguna» (art. 129.1 LCSP).

Además las proposiciones son secretas, salvo en el caso de la subasta electrónica o en el diálogo competitivo (art. 129.2 LCSP). Por tanto, luego se celebrará un acto público de apertura de proposiciones, tal como regula el art. 83 RGLCAP.

Asimismo, ahora en esta sede de proposiciones, el art. 131 contempla la admisión de variantes, en términos muy cercanos al anterior art. 87 del TRLCAP.

La proposición deberá ir acompañada de los documentos precisos para garantizar la capacidad jurídica y de obrar, la solvencia económica, financiera y técnica, la inexistencia de prohibiciones de contratar y el sometimiento a la jurisdicción de los Tribunales españoles en el caso de empresas extranjeras (art. 130), en términos muy similares a los establecidos por el art. 79.2 del TRLCAP, que ahora recibe mayor explicitación en los apartados 2 y 3 del artículo 130 
SELECCIÓN DE CONTRATISTAS Y ADJUDICACIÓN DE CONTRATOS...

LCSP. Por otra parte, deben tenerse en cuenta las disposiciones del RGLCAP relativas a la presentación de proposiciones, en especial, en relación con su forma, subsanación de defectos, apertura y rechazo de proposiciones (arts. 80-84).

\subsection{La posibilidad de subasta electrónica}

Una novedad de la LCSP es la introducción de medios electrónicos para la adjudicación de los contratos. Se permite acudir a esta subasta electrónica en los procedimientos abiertos y restringidos y en los procedimientos negociados del artículo 154 a) de la LCSP (art. 132). Como señala expresamente este precepto legal, se trata de un procedimiento «iterativo», es decir, continuado en el que se suceden las ofertas respecto del precio u otros elementos del contrato. Por consiguiente, deberá producirse en un momento determinado el cierre de la subasta, al que seguirá la adjudicación del contrato con arreglo a la oferta económicamente más ventajosa (art. 132.10 y 11).

\subsection{Los criterios de selección del adjudicatario}

En este apartado es preciso diferenciar diferentes cuestiones:

\section{a) Los dos sistemas de selección}

La LCSP rechaza la anterior denominación de «formas de adjudicación» para referirse a la subasta y al concurso como algo diferenciado de los procedimientos de adjudicación (arts. 74 y 75 del TRLCAP). Por otro, se abandona la denominación de subasta y concurso, y se hace referencia a un único ${ }^{19}$ sistema de valoración el de la oferta económicamente más ventajosa, pero por una pura complejidad semántica ${ }^{20}$, cuando en realidad, hay dos sistemas de selección tal

19 J. M. GiMENO FELIU critica la fijación de un único criterio de adjudicación por entender que se separa de lo dispuesto en la Directiva que diferencia de forma muy clara entre dos criterios de adjudicación, la oferta económicamente más ventajosa y el precio más bajo ( «Reflexiones críticas sobre el proyecto de ley de contratos del sector público», en RGDA núm. 14/2007, págs. 29-30).

20 Así lo indica el apartado IV.4 de la exposición de motivos de la LCSP: «Además, y desde un punto de vista formal, se ha aprovechado para incorporar a nuestra legislación la terminología comunitaria de la contratación, con el fin de facilitar, ya desde el plano semántico, la interoperabilidad con los sistemas europeos de contratación. Esto ha supuesto el abandono de ciertas denominaciones tradicionales en nuestro derecho, que no de los correspondientes conceptos, que subsisten bajo nombres más ajustados al contexto europeo. En particular, los términos «concurso» y «subasta» - que en la legislación nacional se referían, de forma un tanto artificiosa, a «formas de adjudicación» del contrato como instrumento que debía utilizarse en conjunción con los «procedimientos de adjudicación», se subsumen en la expresión «oferta económicamente más ventajosa» que remite en definitiva, a los criterios que el órgano de contratación ha de tener en cuenta para valorar las ofertas de los licitadores en los diferentes procedimientos abiertos, restringidos o negociados, y ya se utilice un único criterio (el precio, como en la antigua «subasta») o ya se considere una multiplicidad de ellos (como en el antiguo «concurso») - . El concepto legal de «oferta económicamente más ventajosa» es, sin embargo, más amplio que el manejado en la Directiva 2004/18, englobando tanto la noción estricta presente en la norma comunitaria - que presupone la utilización de una multiplicidad de 
como expresamente indica el art. 53 de la Directiva 2004/18/CE ${ }^{21}$ que se refiere a ellos denominándolos criterios de adjudicación:

1) El antiguo concurso, es decir, la aplicación de varios criterios de adjudicación que se relacionan de forma enunciativa en el art. 134.1 párrafo $1 .^{\circ}$ LCSP.

2) La antigua subasta, es decir, la aplicación de un solo criterio de adjudicación, que es el precio.

Esta posición de la Directiva queda más claramente reflejada en el art. 135.1 LCSP al referirse a la adjudicación de los contratos.

\section{b) Los criterios de selección o adjudicación}

Las novedades de la LCSP respecto del TRLCAP se centran en los siguientes aspectos:

1) Mayores exigencias en cuanto a la delimitación previa de los criterios de adjudicación e, incluso, de su valoración previa o cuando menos su ordenación de forma decreciente (apartados 2, 4 y 5 del art. 134 LCSP). Se trata de asegurar dos aspectos principales: que sólo pueden fijarse criterios objetivos (no subjetivos) ${ }^{22}$, aunque se admitan también los aspectos medioambientales y sociales $^{23}, y$, además, que debe hacerse esta fijación con absoluta transparencia a fin de que todos los licitadores conozcan previamente los criterios y su ponderación (apartado 46 de la exposición de motivos de la Directiva 2004/18/CE) ${ }^{24}$. La

parámetros de valoración - , como el criterio del «precio más bajo», que dicha disposición distingue formalmente de la anterior; la Ley ha puesto ambos conceptos comunitarios bajo una misma rúbrica para evitar forzar el valor lingüístico usual de las expresiones utilizadas (no se entendería que la oferta más barata, cuando el único criterio a valorar sea el precio, no fuese calificada como la «económicamente más ventajosa»), y para facilitar su empleo como directriz que resalte la necesidad de atender a criterios de eficiencia en la contratación».

21 El apartado 46 de la Directiva lo expresa correctamente: «La adjudicación del contrato debe efectuarse basándose en criterios objetivos que garanticen el respeto de los principios de transparencia, no discriminación e igualdad de trato, así como la evaluación de las ofertas en condiciones de competencia efectiva. Por consiguiente, conviene admitir únicamente la aplicación de dos criterios de adjudicación, a saber, el del precio más bajo y el de la oferta económicamente más ventajosa» (párrafo $1 .^{\circ}$ ).

22 Por eso de forma muy acertada, DEL SAZ ha advertido el error del art. 174.1.a) LCSP que se refiere a «criterios subjetivos», lo que es contrario a la Directiva comunitaria («La nueva Ley de Contratos del Sector Público. ¿Un nuevo traje con las mismas rayas?», cit., p. 345)

23 Pueden ser criterio de adjudicación y así lo ha admitido el TJCE (Sentencia 17 de septiembre de 2002Asunto Concordia), pero también pueden ser cláusulas contractuales previstas en los pliegos que operan como requisitos de contratación. En este sentido se prevén en el art. 50 de la Directiva como normas de gestión ambiental y no se incluyen en su art. 53 relativo a los criterios de adjudicación de los contratos. La exposición de motivos de la LCSP afirma que es una novedad «la previsión de mecanismos que permiten introducir en la contratación pública consideraciones de tipo social y medioambiental, configurándolas como condiciones especiales de ejecución del contrato o como criterios para valorar las ofertas» (apartado IV.3).

24 Téngase en cuenta lo previsto en el art. 37.1 de la Ley catalana 3/2007, de 4 de julio, de la obra pública, respecto a la fijación de la ponderación de los criterios de valoración. 
SELECCIÓN DE CONTRATISTAS Y ADJUDICACIÓN DE CONTRATOS...

Sentencia del TJCE de 24 de enero de 2008 (C-532/06) insiste en dos cuestiones importantes y reiteradas a este respecto:

- la experiencia no es un criterio de adjudicación del contrato (apartado 32).

- no cabe la fijación a posteriori de los coeficientes de ponderación de los criterios de adjudicación, sino que éstos deben ser conocidos por los licitadores en el momento de presentar sus ofertas, a fin de que estén en pie de igualdad a lo largo de todo el procedimiento (apartados 36 y 40).

2) Se contempla un mayor número de supuestos en que debe acudirse a más de un criterio de adjudicación (ocho supuestos del art. 134.3 LCSP por cuatro supuestos del art. 85 TRLCAP).

3) Posibilidad de imponer penalidades por incumplimiento de los criterios de adjudicación (art. 134.6 LCSP).

c) La valoración de los criterios de adjudicación: Mesa de contratación y Comisión de expertos

La valoración de los criterios de adjudicación la efectuará normalmente la Mesa de contratación. El art. 295 LCSP impone su constitución para los procedimientos abiertos y restringidos y negociados con publicidad, y asimismo para el diálogo competitivo se contempla una Mesa especial (art. 296). En los procedimientos negociados sin publicidad su composición es potestativa. Estos preceptos determinan su composición en sus aspectos básicos.

Para el ámbito local, su composición viene fijada por la D.A. $22^{\circ} .10$ que mantiene en líneas generales las previsiones de la D.A. 9..$^{\text {a }} 3$ del TRLCAP. La novedad que se introduce por la LCSP radica en la posibilidad de integrar en estas Mesas de contratación a personal de las Diputaciones Provinciales o de las Comunidades Autónomas uniprovinciales (apartado 9, párrafo 2. ${ }^{\circ}$ ).

La LCSP ha introducido una importante novedad al exigir la intervención de un comité de expertos para la valoración de los criterios de adjudicación cuando su cuantificación dependa de un criterio de valor:

«En la determinación de los criterios de adjudicación se dará preponderancia a aquellos que hagan referencia a características del objeto del contrato que puedan valorarse mediante cifras o porcentajes obtenidos a través de la mera aplicación de las fórmulas establecidas en los pliegos. Cuando en una licitación que se siga por un procedimiento abierto o restringido se atribuya a los criterios evaluables de forma automática por aplicación de fórmulas una ponderación inferior a la correspondiente a los criterios cuya cuantificación dependa de un juicio de valor, deberá constituirse un comité que cuente con un mínimo de tres miembros, formado por expertos no integrados en el órgano proponente del contrato y con cualificación apropiada, al que correspon- 
derá realizar la evaluación de las ofertas conforme a estos últimos criterios, o encomendar esta evaluación a un organismo técnico especializado, debidamente identificado en los pliegos» (art. 134.2 párrafo $2 .^{\circ}$ ).

\subsection{La adjudicación de los contratos: provisional y definitiva}

Una de las novedades más sobresalientes de la LCSP en relación con el TRLCAP es la división de la adjudicación en dos fases: adjudicación provisional y definitiva. Basta a tal efecto comparar el enorme contraste entre la regulación actual del art. 135 LCSP con la anterior del art. 88 del TRLCAP. La LCSP divide la adjudicación del contrato en dos momentos o fases:

\section{a) Adjudicación provisional}

Se trata de una adjudicación «provisional» que debe notificarse y publicarse (art. 135.3). Sirve a los efectos de la presentación de los documentos que justifiquen los requisitos así como de la garantía que haya de establecerse y también para permitir la articulación de recursos contra la misma de modo que no se pase de inmediato a la adjudicación definitiva dejándolos sin sentido. Esta adjudicación provisional cobra sentido en relación con el recurso especial en materia de contratación, que contempla como actos recurribles de este nuevo recurso obligatorio los acuerdos de adjudicación provisional (art. 37.2 LCSP) y al que se refiere de forma expresa el art. 135.4 LCSP. Debe tenerse en cuenta que el art. 37.4 LCSP determina la suspensión automática de la tramitación del expediente de contratación cuando se recurra el acto de adjudicación provisional.

\section{b) Adjudicación definitiva}

Se produce transcurrido un plazo (10, 15 días o un mes) a partir de la adjudicación provisional.

Por otra parte se establecen cuatro reglas respecto de la adjudicación:

a) Imposibilidad de declarar desierta la licitación: el artículo 135.2 LCSP señala que «el órgano de contratación no podrá declarar desierta una licitación cuando exista alguna oferta o proposición que sea admisible de acuerdo con los criterios que figuren en el pliego». Con ello se deja sin efecto la posibilidad de dejar desiertos los concursos que preveía el art. 88.2 TRLCAP.

b) Ofertas con valores anormales o desproporcionados: el artículo 135.3 LCSP permite no adjudicar el contrato a un licitador cuando su oferta tenga valores anormales o desproporcionados que permitan concluir fundadamente que el contrato no podrá ser cumplido ${ }^{25}$. Más adelante el artículo 136 LCSP

25 Téngase en cuenta lo previsto en el art. 38.3 y 4 de la Ley catalana 3/2007, de 4 de julio, de la obra pública, sobre «las ofertas anormalmente bajas». 
SELECCIÓN DE CONTRATISTAS Y ADJUDICACIÓN DE CONTRATOS...

define qué se entiende por ofertas con valores anormales o desproporcionados. Se sigue, en definitiva, lo previsto en el artículo 83 TRLCAP, aunque ahora se resuelve de forma clara la duda existente en el TRLCAP de si las bajas temerarias eran también aplicables en los concursos, dado que el precepto se encontraba en sede de subasta y, además, el artículo 90 RGLCAP así lo sostenía. Así pues en la LCSP se aplica tanto en los supuestos de existencia de un único criterio de adjudicación (el precio, o sea, la subasta) o haya varios criterios de adjudicación (el concurso). Lo más importante es la audiencia al licitador, antes de rechazar su oferta. Además se suprime la exigencia de una garantía especial para estos casos que preveía el art. 83.5 del TRLCAP.

c) Adjudicación al licitador siguiente en el orden: el art. 135.5 LCSP recoge una norma muy similar a la prevista en el art. 84 TRLCAP para la subasta consistente en la adjudicación del contrato al licitador siguiente en el orden resultante de la aplicación del criterio o criterios de adjudicación. No obstante, se observan dos diferencias importantes respecto de la regulación precedente:

- Como la LCSP distingue ente la adjudicación provisional y la definitiva, en estos casos ya no se produce resolución, sino un simple ejercicio de una práctica de «correr la lista».

- También se permite esta sustitución del adjudicatario cuando se produzca la resolución del contrato ya iniciado, pero sólo para los contratos no sujetos a regulación armonizada.

d) Renuncia o desistimiento de la Administración: se contempla en el art. 139 LCSP y constituye una importante novedad respecto del TRLCAP. La Administración puede renunciar al contrato o desistir del procedimiento de adjudicación antes de la adjudicación provisional. Se trata en ambos casos de dos vías que precisan del cumplimiento de los requisitos materiales y formales contemplados en dicho precepto legal. La renuncia se prevé de una forma excesivamente amplia: la concurrencia de razones de interés público debidamente justificadas en el expediente. Por el contrario, el desistimiento obedece a la existencia de infracción que pretende subsanarse con la apertura de un nuevo procedimiento.

\subsection{Notificación y publicidad de las adjudicaciones}

Esta materia regulada antes en el artículo 93 TRLCAP ahora se desdobla en dos preceptos, los artículos 137 y 138 LCSP.

El artículo 137 se refiere a la notificación del resultado de la adjudicación a los candidatos o licitadores, cuestión que se coloca dentro de un marco más amplio: el cumplimiento de la obligación de información. Esta obligación se encuentra en íntima relación con el principio de transparencia consagrado en el art. 123 LCSP. Además se ofrece la posibilidad de información adicional si así 
lo solicitan los licitadores, en términos muy similares a la regulación anterior (apartados 1 y 5 del art. 93 TRLCAP).

La novedad se encuentra en una mayor precisión respecto de una de las preocupaciones de la nueva Ley, cual es la confidencialidad (art. 124) que ahora se reitera como una obligación de no comunicación para el órgano de contratación (art. 137.2 LCSP), que se extiende también a la publicación del anuncio de adjudicación (art. 138.4 LCSP).

La regulación de la publicidad vuelve de nuevo a tener en cuenta el escalonamiento contractual a que me he referido más arriba:

1) Contratos menores: no son objeto de publicidad.

2) Contratos superiores en cuantía a los contratos menores: la adjudicación debe ser publicada en el perfil de órgano de contratación.

3) Contratos en cuantía igual o superior a 100.000 euros (más los contratos de gestión de servicios públicos de duración superior a cinco años): la adjudicación debe ser publicada en el BOE o en los Diarios Oficiales de la Comunidad Autónoma o de la Provincia. Puede verse que la cuantía se eleva de forma notable, dado que el TRLCAP contemplaba la de 60.101 euros (art. 93.2). El plazo para la publicación es idéntico: 48 días como máximo desde la adjudicación del contrato.

4) Contratos sujetos a regulación armonizada: la adjudicación deberá ser publicada en el DOUE y en el BOE.

5) Contratos de servicios de las categorías 17 a 27 del Anexo II y de cuantía superior a 206.000 euros: son contratos que se han excluido de la categoría de contratos sujetos a regulación armonizada dado que, aunque están incluidos en la Directiva 2004/18/CE, ésta sólo se les aplica en cuanto a las especificaciones técnicas y en este punto, es decir, en la necesidad de comunicar la adjudicación definitiva a la Comisión Europea.

\subsection{Formalización del contrato}

El art. 140 LCSP$^{26}$ regula la formalización de los contratos, que es presupuesto para su ejecución (apartado 4, con la excepción de los supuestos de contratación urgente o de emergencia), en claro continuismo con el art. 54 del TRLCAP. Se exige la formalización en documento público de todos los contratos, excepto los contratos menores en los que bastará la factura. El contratista podrá exigir, a su costa, que se eleve a escritura pública.

26 Este precepto no tiene carácter básico, según indica la disposición final 7. a . LCSP. 
SELECCIÓN DE CONTRATISTAS Y ADJUDICACIÓN DE CONTRATOS...

La falta de formalización del contrato puede dar lugar a la resolución del contrato, que podrá ser imputable al contratista o a la Administración. El apartado 3 párrafo $1 .^{\circ}$ de este precepto legal al regular la resolución del contrato por causa imputable al contratista exige, en caso de que éste se oponga, la intervención del Consejo de Estado o del Consejo Consultivo de la Comunidad Autónoma correspondiente ${ }^{27}$.

\section{LOS DIFERENTES PROCEDIMIENTOS DE ADJUDICACIÓN}

Antes de entrar a examinar cada uno de los procedimientos, es preciso reiterar la advertencia de la diferente estructura normativa de la LCSP respecto de su precedente el TRLCAP. Mientras en éste último muchas de las normas sobre los diferentes procedimientos de adjudicación estaban contenidas dentro de la regulación propia de cada uno de los contratos administrativos, ahora en la LCSP se efectúa una regulación general procedimental sin que la misma esté unida a ninguno de los contratos administrativos nominados. Es, por ello, que ahora se elevan a normas «generales» algunas disposiciones que antes venían referidas a cada categoría de contrato administrativo en el Libro II del TRLCAP.

Por otra parte, aquí no se va a seguir el orden expositivo de la LCSP sino que se va a partir de un análisis de los diferentes procedimientos de adjudicación desde la perspectiva de las entidades locales, explicándose dichos procedimientos desde su mayor simplicidad hacia su mayor complejidad. De ahí que se proceda a diferenciar los procedimientos de la LCSP en tres grupos o categorías en razón de la simplificación administrativa procedimental:

a) Procedimientos simplificados: lo son los contratos menores y los procedimientos negociados sin publicidad.

b) Procedimientos no simplificados: lo son el procedimiento negociado con publicidad y los procedimientos abiertos y restringidos.

c) Procedimientos complejos: cabe incluir aquí el diálogo competitivo.

\subsection{Los procedimientos simplificados de adjudicación}

\subsubsection{Los contratos menores}

Conforme establece el art. 122.3 párrafo $3 .^{\circ}$ de la LCSP «se consideran contratos menores los contratos de importe inferior a 50.000 euros, cuando se

27 Este precepto debe entenderse como una aclaración «extensiva» de lo ya dispuesto en el art. 195.3 LCSP. 
trate de contratos de obras, o a 18.000 euros, cuando se trate de otros contratos» ${ }^{28}$.

Puede verse cómo la LCSP ha incrementado notablemente las cuantías de estos contratos menores (antes 30.050 euros para los contratos de obras y 12.020 euros para los contratos de suministro y de servicios).

La regulación material de estos contratos por la LCSP (art. 95) es prácticamente similar a la anterior del TRLCAP (art. 56), exigiéndose unos requisitos mínimos: aprobación del gasto y factura y, cuando se trate de obras, presupuesto, proyecto si es necesario y supervisión del mismo.

Esto significa que gran parte de los contratos que celebren las entidades locales se efectuarán con arreglo a este sistema sencillo y ágil.

Se mantiene la prohibición de revisión de precios (art. 77.2 LCSP), pero se suprime la limitación temporal de duración superior a un año que se recogía en el art. 56 del TRLCAP.

Finalmente, debe tenerse en cuenta lo dispuesto en el art. 72 del RGLCAP sobre los requisitos de las facturas.

\subsubsection{El procedimiento negociado sin publicidad}

La LCSP (art. 153) define el procedimiento negociado en similares términos a los ya contenidos en el art. 73.4 del TRLCAP: se consulta a varios empresarios y se negocian con ellos las condiciones del contrato. Diferencia dos tipos de procedimiento negociado: con publicidad y sin publicidad.

Ahora va a hacerse referencia al procedimiento negociado sin publicidad por constituir un procedimiento simplificado, por tres razones:

a) Se limitan de forma importante los requisitos procedimentales, dado que no se precisa publicación de los anuncios de contratación y se negocian las condiciones del contrato con los licitadores.

b) Sólo se exige la solicitud de ofertas a tres empresas (arts. 153.2 párrafo $2 .^{\circ}$ y 162.1 LCSP).

c) La constitución de Mesa de contratación es potestativa (art. 295.1 LCSP).

La limitación de la publicidad y de la concurrencia provocan que este procedimiento deba ser considerado excepcional ${ }^{29}$, es decir, sólo se puede acudir

\footnotetext{
28 Las cuantías establecidas en este apartado 3 tienen carácter básico, solamente en cuanto máximos, por lo que pueden ser rebajadas por la legislación autonómica (disposición final 7. ‥2. párrafo 2. ${ }^{\circ}$ ).

29 Así lo indica la Sentencia del TJCE de 8 de abril de 2008 (C-337/05), que condena a Italia por incumplimiento del Derecho Comunitario derivado por haber acudido a este procedimiento negociado:
} 


\section{SELECCIÓN DE CONTRATISTAS Y ADJUDICACIÓN DE CONTRATOS...}

al mismo en los concretos supuestos previstos en la LCSP. En otro caso el recurso a este procedimiento provocará la nulidad de pleno derecho del procedimiento de adjudicación, puesto que se prescinde total y absolutamente del procedimiento establecido (art. 32 LCSP y art. 62.1.e) LRJPAC).

Interesa, por tanto, averiguar cuáles son los supuestos en que se puede acudir a este procedimiento negociado sin publicidad ${ }^{30}$. Son los siguientes:

a) Con carácter general: los supuestos contemplados en las letras c) a g) del art. 154 LCSP.

b) Con carácter específico, para los contratos de obras (art. 155), de gestión de servicios públicos (art. 156), de suministro (art. 157) y de servicios (art. 158) todos los supuestos previstos en dichos preceptos, excepto los de la letra a) de los arts. 155 y 158. Asimismo se establecen límites respecto de la cuantía:

1) Contrato de obras: desde 50.000 euros (contratos menores) hasta 200.000 euros (art. 161.2 en relación con el art. 155 d) LCSP).

2) Restantes contratos: desde 18.000 euros (contratos menores) hasta 60.000 euros (art. 161.2 en relación con los arts. 156 b), 157 f), 158 e) y 159 LCSP).

«56. Según se desprende, en particular, del duodécimo considerando de la exposición de motivos de la Directiva 93/36, el procedimiento negociado deberá considerarse excepcional y, por lo tanto, sólo deberá aplicarse en aquellos casos taxativamente enumerados. A tal fin, conviene señalar que, en el artículo 6, apartados 2 y 3, de la citada Directiva, se enumeran limitativa y expresamente las únicas excepciones en las que esté autorizada la utilización del procedimiento negociado (véase, por lo que atañe a la Directiva 77/62, la sentencia de 17 de noviembre de 1993, Comisión/España, C-71/92, Rec. p. I-5923, apartado 10; en lo que se refiere a la Directiva 93/36, véanse las sentencias, antes citadas, Teckal, apartado 43, y de 13 de enero de 2005, Comisión/España, apartado 47).

57. Según la jurisprudencia del Tribunal de Justicia, las excepciones a las normas que tienen como finalidad garantizar la efectividad de los derechos reconocidos por el Tratado en el sector de los contratos públicos deben ser objeto de una interpretación restrictiva (véanse las sentencias de 18 de mayo de 1995, Comisión/Italia, C-57/94, Rec. p. I-1249, apartado 23; de 28 de marzo de 1996, Comisión/Alemania, C-318/94, Rec. p. I-1949, apartado 13, y de 2 de junio de 2005, Comisión/Grecia, C-394/02, Rec. p. I-4713, apartado 33). Por lo tanto, los Estados miembros no pueden prever unos supuestos de utilización del procedimiento negociado no previstos en la citada Directiva, como tampoco establecer para los supuestos expresamente previstos por la Directiva nuevas condiciones que tengan por efecto hacer más cómoda la utilización del citado procedimiento (véase, en este sentido, la sentencia de 13 de enero de 2005, Comisión/España, antes citada, apartado 48).

58. Procede recordar, además, que la carga de la prueba de que se dan efectivamente las circunstancias excepcionales que justifican tal excepción incumbe a quien pretenda alegar la citada excepción (véanse las sentencias de 10 de marzo de 1987, Comisión/Italia, 199/85, Rec. p. 1039, apartado 14, y Comisión/ Grecia, antes citada, apartado 33)».

Asimismo, la Sentencia del TJCE de 18 de diciembre de 2007 (C-481/05) condena por idéntica razón a Francia.

30 Téngase en cuenta lo previsto en el art. 31 de la Directiva 2004/18/CE relativo a los casos que justifican el recurso al procedimiento negociado sin publicación de un anuncio de licitación. 
Especial atención ${ }^{31}$ merece el supuesto de la letra e) del art. 154 LCSP que dice así: "Cuando una imperiosa urgencia, resultante de acontecimientos imprevisibles para el órgano de contratación y no imputables al mismo, demande una pronta ejecución del contrato que no pueda lograrse mediante la aplicación de la tramitación de urgencia regulada en el artículo 96».

Debe repararse en la importante diferencia que se produce respecto del art. 141 c) del TRLCAP (relativo al contrato de obras y demás preceptos concordantes del TRLCAP referidos a los demás contratos de las Administraciones Públicas). Ahora se exige que los acontecimientos sean no sólo imprevisibles (como se exigía antes) sino también que no sean imputables al ente público (la novedad). Se trata de incorporar las exigencias de la Directiva 2004/18/CE ${ }^{32}$ y, además, la doctrina fijada al respecto por el $\mathrm{TJCE}^{33}$.

Además para el ámbito local, la disposición adicional 2. ${ }^{\text {. } 9 ~ L C S P ~}$ LC $^{34}$ exige para el procedimiento negociado en supuestos de urgencia que se incorporen los informes del secretario (o titular de la asesoría jurídica) y del interventor.

Este procedimiento negociado sin publicidad pasará, junto con el contrato menor, a ser la figura ordinaria de contratación en el ámbito local, una vez desaparecido el límite general del 10\% de los recursos ordinarios del presupuesto para poder acudir a este procedimiento negociado ${ }^{35}$.

31 ORTEGA MONTORO afirma que este supuesto es el que cuantitativamente más se ha utilizado para justificar el recurso al procedimiento negociado ( «La contratación de las Entidades Locales en la nueva Ley de Contratos del Sector Público 30/2007, de 30 de octubre: Sus especialidades», cit., pág. 36).

32 Se transpone lo establecido por el art. 31.1, letra c) de la Directiva que textualmente se refiere a: «Las circunstancias alegadas para justificar la urgencia no deberán en ningún caso ser imputables a los poderes adjudicadores».

33 El TJCE, en una jurisprudencia muy reiterada, ha fijado los requisitos para que pueda acudirse al procedimiento negociado por urgencia. Así por ejemplo la Sentencia 28-marzo-1996 (Asunto C-318/94) reitera estos requisitos:

«El Tribunal de Justicia también ha declarado que la excepción prevista por la letra d) del artículo 9 de la Directiva 71/305, a saber, la dispensa de la obligación de publicar un anuncio de licitación, está supeditada al cumplimiento de tres requisitos acumulativos. En efecto, supone la existencia de un acontecimiento imprevisto, de una imperiosa urgencia incompatible con los plazos requeridos en otros procedimientos y, por último, de una relación de causalidad entre el acontecimiento imprevisto y la imperiosa urgencia que deriva de éste.... Si no se cumple uno de los requisitos, el recurso al procedimiento negociado no está justificado» (apartado 14).

34 Un examen general de esta disposición adicional 2. ${ }^{\text {a }}$ puede verse en E. CORRAL GARCíA, «La contratación local en la nueva Ley de Contratos del Sector Público», en El Consultor, núm. 23, 15 diciembre 2007, págs. 3905-3912 y en S. ROMERo HERNÁNDEZ, «Aplicación de la nueva Ley de Contratos del Sector Público a las Entidades Locales», en Noticias Jurídicas, Enero 2008, págs. 1-30.

35 Así lo indica CORRAL GARCíA, quien afirma que «...es lo cierto que al desparecer el límite general del $10 \%$ de los recursos ordinarios del Presupuesto para poder utilizar el procedimiento negociado por razón de la cuantía, al incrementarse de formar espectacular el límite específico de cada contrato tipificado, especialmente el de obras, el procedimiento negociado sin publicidad vendrá a resolver y satisfacer las necesidades contractuales del 90\% de las Entidades locales» («La contratación local en la nueva Ley de Contratos del Sector Público», cit., pág. 3912). En idéntico sentido ORTEGA MONTORO resalta la expansión de los procedi- 


\subsection{Los procedimientos no simplificados}

\subsubsection{El procedimiento negociado con publicidad}

Se trata de un procedimiento negociado y como tal excepcional, es decir, sólo se permite en los supuestos previstos específicamente en la LCSP $^{36}$. La publicidad es obligada y, además, de esta publicidad se derivan diversas reglas:

1) Puede presentar ofertas cualquier empresario interesado (art. 153.2 LCSP).

2) Se aplican las normas del procedimiento restringido, en concreto, los arts. 147-150 LCSP. Es, por tanto, un procedimiento no simplificado, puesto que habrá que cumplir no sólo la publicidad sino los trámites del procedimiento restringido.

Los supuestos de este procedimiento negociado con publicidad son los de las letras a) y b) del art. 154 (supuestos generales), de la letra a) del art. 155 (contrato de obras) y de la letra a) del art. 158 (contrato de servicios), aunque se admite una excepción en que puede prescindirse del anuncio de licitación (párrafo $2 .^{\circ}$ del art. 161.1 LCSP).

La exposición de motivos de la LCSP señala que articula «un nuevo procedimiento negociado con publicidad para contratos no sujetos a regulación armonizada que no superen una determinada cuantía publicidad» (apartado IV.4), por lo que hay que acudir a la importante división entre contratos sujetos a regulación armonizada y no sujetos a regulación armonizada. Así, con base en esta división cabe afirmar que la publicidad se impone en los siguientes casos:

a) Contratos sujetos a regulación armonizada: sólo será necesario anuncio de licitación en el DOUE y en el BOE en los casos de contratos que estén incluidos en los preceptos referidos en el párrafo $10^{\circ}$ del art. 161.1 LCSP, que debe entenderse acoge el contenido del art. 30 de la Directiva 2004/18/CEE que exige en estos supuestos la previa publicación de un anuncio de licitación. En los demás supuestos no será necesaria la publicidad (supuestos especificados en el art. 31 de la misma Directiva, antes expuestos). Además deberá publicarse en el perfil del órgano de contratación.

b) Contratos no sujetos a regulación armonizada: será necesario anuncio de licitación en el BOE o en los Diarios Oficiales de la Comunidad Autónoma o de la Provincia en los casos de contratos que estén incluidos en los preceptos

mientos simplificados de contratación ( «La contratación de las Entidades Locales en la nueva Ley de Contratos del Sector Público 30/2007, de 30 de octubre: Sus especialidades», cit., págs. 39-41).

36 Téngase en cuenta lo previsto en el art. 30 de la Directiva 2004/18/CE relativo a los casos que justifican el recurso al procedimiento negociado con publicación de un anuncio de licitación. 
referidos en el párrafo $1 .^{\circ}$ del art. 161.1 LCSP así como en aquellos previstos en su apartado 2. También se precisará la publicación del anuncio en el perfil del órgano de contratación, que podrá ser sustitutivo del anuncio en los Diarios Oficiales en los supuestos del art. 161.2 (art. 126.4 LCSP).

Por tanto, en razón de la cuantía, este procedimiento negociado con publicidad para contratos no sujetos a regulación armonizada se aplica en los siguientes casos:

a) Contratos de obras: desde 200.000 euros hasta un millón de euros.

b) Contrato de gestión de servicios públicos: desde 60.0000 euros hasta 500.000 euros (de gastos de primer establecimiento) y plazo de duración inferior a cinco años.

c) Restantes contratos: desde 60.000 euros hasta 100.000 euros.

Como puede verse, este procedimiento negociado con publicidad es un procedimiento formalizado que debe seguir una determinada tramitación que en parte se acerca a los procedimientos restringidos, y además se precisa la constitución preceptiva de Mesa de contratación (art. 295.1 LCSP).

\subsubsection{El procedimiento abierto}

A diferencia de lo que ocurría en el TRLCAP, la LCSP dedica una Sección

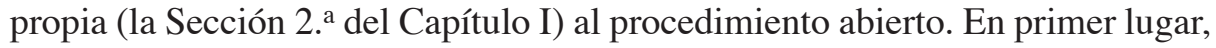
el art. 141 LCSP define qué es el procedimiento abierto con una terminología muy cercana a lo que ya disponía el art. 72.2 del TRLCAP. Simplemente conviene precisar la adición que efectúa ahora la LCSP: «...quedando excluida toda negociación de los términos del contrato con los licitadores».

En esta regulación del procedimiento abierto cabe destacar los siguientes aspectos:

a) Información adicional: el art. 142 regula la información a los licitadores y contempla que éstos puedan solicitar información adicional, en cuyo caso la dación de esta información incide en el plazo de presentación de ofertas puesto que se prevé su prórroga.

b) Plazos de presentación de proposiciones: se diferencia según se trate de contratos sujetos a regulación armonizada, donde los plazos no pueden ser inferiores a 52 días (con diversas posibilidades de reducción), o no sujetos a regulación armonizada, donde los plazos no podrán ser inferiores a 15 días, excepto en los contratos de obras y concesión de obras públicas en que será de 26 días (art. 143 LCSP). 
SELECCIÓN DE CONTRATISTAS Y ADJUDICACIÓN DE CONTRATOS...

c) Normas específicas sobre la tramitación y la adjudicación: los artículos 144 y 145 LCSP contemplan diversas normas específicas que completan la regulación «general» sobre tramitación y adjudicación de los contratos. Se trata de una regulación que recoge en sus aspectos principales la antes contenida en el TRLCAP. Así el art. 144.2 LCSP reitera que la propuesta de adjudicación no crea derecho alguno a favor del licitador propuesto, recogiendo lo que disponían los arts. 82.2. y 81.3 TRLCAP.

No obstante, la LCSP reduce los plazos de adjudicación provisional (antes no existía este trámite, luego los plazos se fijaban para la adjudicación definitiva) que serán de 15 días (antes 20 días) para el caso de criterio único de precio (antes subasta en el art. 83.1 TRLCAP) y de 2 meses (antes 3 meses) para el caso de diversos criterios de adjudicación (antes concurso en el art. 89.1 TRLCAP). Para ambos casos la LCSP reitera idéntica sanción: el licitador propuesto podrá retirar su proposición (se elimina la referencia a la garantía, dado que ahora la garantía se presta tras la adjudicación provisional).

\subsubsection{El procedimiento restringido}

El art. 146 LCSP define el procedimiento restringido en términos muy similares a los ya contenidos en el art. 73.3 TRLCAP, añadiendo dos precisiones. La primera de ellas relativa a que la selección de los candidatos se efectuará «en atención a su solvencia» y, por otra parte, imponiendo idéntica fórmula que para el procedimiento abierto en el sentido de que no hay negociación.

Seguidamente se establecen las siguientes disposiciones específicas de este procedimiento de adjudicación:

a) Criterios de selección de candidatos: el art. 147 LCSP sigue muy de cerca las previsiones del art. 91 del TRLCAP con leves modificaciones (no contiene un número máximo y exige que los criterios y número mínimo y máximo de licitadores se indique en el anuncio de licitación).

b) Plazos de presentación de solicitudes de participación: aquí se recogen con carácter «general» las reglas antes dispersas para cada contrato administrativo típico en el TRLCAP. De nuevo se diferencia entre los contratos sujetos a regulación armonizada (plazo no inferior a 37 días, excepto en el contrato de concesión de obra pública que es de 52 días) y no sujetos (plazo mínimo de 10 días).

c) Selección de candidatos para ser licitadores: debe ser por lo menos un número que alcance el mínimo establecido (art. 149 LCSP), aunque el procedimiento puede seguir con un número inferior cuando no haya candidatos que cumplan los criterios de selección.

d) Invitaciones a los candidatos seleccionados: el art. 150 LCSP determina el contenido mínimo de las invitaciones a los candidatos seleccionados y la 
información que debe ofrecerles el órgano de contratación, a fin de que puedan presentar sus proposiciones. Esta información debe ser directa (entrega de los pliegos o documentación) o indirecta (remisión a página web) y, además, también debe preverse la posibilidad de ofrecer información adicional (art. 150.4).

e) Plazos de presentación de proposiciones: de nuevo se diferencia entre contratos sujetos a regulación armonizada (plazo no inferior a 40 días, con diversas posibilidades de reducción) y no sujetos (plazo no inferior a 15 días) (art. 151 LCSP).

f) Adjudicación: se realiza una remisión a las disposiciones específicas del procedimiento abierto, excepto la calificación de documentos puesto que ya se ha efectuado en la fase previa de selección de candidatos (art. 152 LCSP).

\subsection{El procedimiento complejo: el diálogo competitivo}

Está previsto en los artículos 163-167 LCSP y constituye una de sus novedades principales, que se toma del art. 39 de la Directiva 2004/18/CE. La exposición de motivos de la LCSP destaca su aspecto novedoso e indica lo siguiente: «...el diálogo competitivo, pensado para contratos de gran complejidad en los que la definición final de su objeto sólo puede obtenerse a través de la interacción entre el órgano de contratación y los licitadores» (apartado IV.3) ${ }^{37}$.

Consiste en que «el órgano de contratación dirige un diálogo con los candidatos seleccionados, previa solicitud de los mismos, a fin de desarrollar una o varias soluciones susceptibles de satisfacer sus necesidades y que servirán de base para que los candidatos elegidos presenten una oferta» (art. 163.1 LCSP). Por ello se permite el pago de primas o compensaciones para los participantes en el diálogo.

\subsubsection{Supuestos de diálogo competitivo}

Este procedimiento de adjudicación tiene un carácter excepcional, limitado solamente a los supuestos previstos en el art. 164 LCSP. No obstante, constituye

37 Más amplia es la explicación de la exposición de motivos de la Directiva 2004/18/CE: «A los poderes adjudicadores que ejecuten proyectos particularmente complejos puede resultarles objetivamente imposible, sin que por ello se los pueda criticar, definir los medios adecuados para satisfacer sus necesidades o evaluar las soluciones técnicas, financieras y jurídicas que pueda ofrecer el mercado. Esta situación puede presentarse, en particular, en la ejecución de importantes infraestructuras de transporte integrado, de redes informáticas de gran tamaño o de proyectos que requieran financiación compleja y estructurada, cuyo montaje financiero y jurídico no es posible definir con antelación. En la medida en que la utilización de procedimientos abiertos o restringidos no permita la adjudicación de dichos contratos, es conveniente pues prever un procedimiento flexible que salvaguarde tanto la competencia entre los operadores económicos como la necesidad de los poderes adjudicadores de debatir con cada candidato todos los aspectos del contrato. No obstante, no se debe recurrir a este procedimiento de manera que se restrinja o falsee la competencia, especialmente mediante modificaciones de elementos fundamentales de las ofertas o imponiendo nuevos elementos sustanciales al licitador seleccionado, o implicando a un licitador distinto del que haya presentado la oferta económicamente más ventajosa» (apartado 31). 
SELECCIÓN DE CONTRATISTAS Y ADJUDICACIÓN DE CONTRATOS...

el procedimiento único para los contratos de colaboración entre el sector público y el sector privado ${ }^{38}$.

Sin embargo, el art. 164 LCSP no ofrece una enumeración de supuestos concretos en los que sea posible acudir al diálogo competitivo, sino que solamente recoge un concepto jurídico indeterminado como es el de «contratos particularmente complejos» ${ }^{39}$. Tampoco el apartado 2 de este precepto aclara mucho más puesto que se limita a señalar un supuesto, que deja además muchas puertas abiertas en su interpretación: «A estos efectos, se considerará que un contrato es particularmente complejo cuando el órgano de contratación no se encuentre objetivamente capacitado para definir, con arreglo a las letras b), c) o d) del apartado 3 del artículo 101, los medios técnicos aptos para satisfacer sus necesidades u objetivos, o para determinar la cobertura jurídica o financiera de un proyecto».

La exposición de motivos de la LCSP ofrece algunos ejemplos (es simplemente enunciativa) de contratos complejos: «ejecución de importantes infraestructuras de transporte integrado, de redes informáticas de gran tamaño o de proyectos que requieran financiación compleja y estructurada, cuyo montaje financiero y jurídico no es posible definir con antelación» ${ }^{40}$.

En todo caso, este procedimiento constituye una alternativa al uso de los procedimientos ordinarios, abiertos y restringidos, y por eso se debe utilizar solamente cuando no quepa dar solución a un determinado contrato mediante estos procedimientos ordinarios. Más aún la Directiva 2004/18/CE incluye en su exposición de motivos una prohibición expresa de acudir a este procedimiento de diálogo competitivo:

«No obstante, no se debe recurrir a este procedimiento de manera que se restrinja o falsee la competencia, especialmente mediante modificaciones de elementos fundamentales de las ofertas o imponiendo nuevos elementos sustanciales al licitador seleccionado, o implicando a un licitador distinto del que haya presentado la oferta económicamente más ventajosa» (apartado 31, in fine).

\subsubsection{Tramitación}

La Directiva 2004/18/CE lo califica de procedimiento flexible, puesto que permite debatir con cada candidato todos los aspectos del contrato (apartado 31 de su exposición de motivos).

\footnotetext{
38 Vid. C. ChINChILla MARÍN, «El nuevo contrato de colaboración entre el sector público y el sector privado», en REDA núm. 132/2006, págs. 609-644 y «La nueva Ley de Contratos del Sector Público: ámbito de aplicación y otras cuestiones novedosas», en Revista Vasca de Administración Pública núm. 79/2007, y págs. 41-69; y J. GONZÁLEZ GARCÍA, «Contrato de colaboración público-privada», en RAP núm. 170/2006, págs. 7-39.

39 Es, por otra parte, la misma regulación que la contenida en el art. 29.1 de la Directiva 2004/18/CE.

40 Los ejemplos se toman del apartado 31 de la exposición de motivos de la Directiva 2004/18/CE.
} 
En este procedimiento hay que diferenciar las siguientes fases ${ }^{41}$ :

1. $\left.{ }^{a}\right)$ Convocatoria. Se precisa anuncio de licitación que determinará la apertura del procedimiento. Aquí los requisitos y necesidades se recogerán en el propio anuncio de licitación o éste remitirá a un documento descriptivo. No hay pliego de cláusulas administrativas particulares, puesto que el elemento esencial es que no se puede definir de antemano el contenido del contrato.

2.a) Solicitudes de participación. Se realiza un procedimiento similar al restringido de selección de candidatos a los que se invitará a participar en el diálogo (el art. 165.2 LCSP se remite a las normas del procedimiento restringido).

3. $\left.{ }^{a}\right)$ Diálogo. Con los candidatos seleccionados se iniciará el diálogo a fin de determinar y definir las soluciones necesarias (art. 166 LCSP). Se trata de que el órgano de contratación pueda, en virtud de este diálogo, estar en situación de determinar cuáles son las soluciones adecuadas (apartado 4, párrafo $1 .^{\circ}$ del art. 166).

4. $\left.{ }^{a}\right)$ Presentación de proposiciones. Una vez definidas las soluciones, se cierra el diálogo y se inicia una nueva fase que es la de presentación de proposiciones por parte de los contratistas. Estos presentarán su oferta final con base en la solución o soluciones presentadas y especificadas durante la fase del diálogo (art. 166.4 párrafo $2 .^{\circ}$ LCSP).

5. $\left.{ }^{a}\right)$ Adjudicación del contrato. Presentadas las proposiciones, se procederá a su evaluación. A tal fin el órgano de contratación estará auxiliado por la Mesa especial del diálogo competitivo prevista en el art. 296 LCSP. El órgano de contratación adjudicará el contrato a la oferta económicamente más ventajosa (no se admite la del precio más bajo), según dispone el art. 167 LCSP. Además, dadas las características especialmente complejas de los contratos adjudicados conforme al diálogo competitivo se contempla la posibilidad de que el órgano de contratación requiera al adjudicatario «para que aclare determinados aspectos de la misma o ratifique los compromisos que en ella figuran, siempre que con ello no se modifiquen elementos sustanciales de la oferta o de la licitación, se falsee la competencia, o se produzca un efecto discriminatorio» (art. 167.3).

\subsection{El procedimiento especial: los concursos de proyectos}

Se regulan de forma específica en los artículos 168-172 LCSP, que siguen la estela ya señalada por el art. 216 del TRLCAP. La nueva regulación transpone

41 Véase la exposición de las fases de adjudicación de un contrato por este procedimiento que efectúa Chinchilla MARín, «El nuevo contrato de colaboración entre el sector público y el sector privado», cit., págs. 637-640. 
SELECCIÓN DE CONTRATISTAS Y ADJUDICACIÓN DE CONTRATOS...

lo dispuesto de forma extensa en los arts. 66-74 de la Directiva 2004/18/CE. Debe advertirse que toda esta regulación versa sobre los concursos de proyectos cuya selección se encomienda a un jurado.

Dos son los aspectos fundamentales de esta regulación de la LCSP:

a) La diferenciación entre contratos sujetos o no a regulación armonizada: para los contratos sujetos a regulación armonizada (siempre que su cuantía sea igual o superior a 206.000 euros, por la remisión que el art. 168.4 efectúa al art. 16 LCSP y una vez actualizada la cuantía a partir de 1 de enero de 2008) se imponen las reglas de publicidad mediante previo anuncio de licitación en DOUE y BOE y, asimismo, del posterior anuncio de adjudicación (art. 171).

b) Composición y actuación del Jurado: el Jurado estará compuesto por personas independientes de los participantes con una cualificación profesional específica para por lo menos un tercio de sus miembros y actuará con autonomía (art. 172). Se regula con detalle su actuación y la vinculación de su propuesta al órgano de contratación que, no obstante, de forma motivada podrá separarse de ella. Más adelante el art. 298 LCSP se refiere a la composición de los Jurados de concursos.

\section{OTROS MODOS O PROCEDIMIENTOS DE ADJUDICACIÓN DE LAS ADMINISTRACIONES PÚBLICAS}

El Título II del Libro III de la LCSP lleva como rúbrica «Racionalización técnica de la contratación» ${ }^{42}$. En realidad acoge bajo dicho manto una serie de modos o procedimientos de adjudicación a los que pueden acudir las Administraciones Públicas, además de los anteriormente previstos. Estos modos o procedimientos de adjudicación son transposición de las disposiciones de la Directiva 2004/18/CE, aunque en algún caso ya se hallaban previstos de forma más o menos completa en el TRLCAP, con excepción del sistema dinámico que es completamente novedoso e idéntica calificación deben recibir los acuerdos marco.

Debe advertirse, en primer término, que son modos o procedimientos de adjudicación que están en posición de igualdad con los anteriormente expuestos. La LCSP realiza una división en dos Títulos de la regulación de los procedimientos de adjudicación. De forma más clara la Directiva comunitaria se refiere a todos ellos de forma conjunta en su Capítulo V sobre «Procedimientos» donde se recogen los procedimientos abiertos, restringidos y negociados y además los acuerdos marco y los sistemas dinámicos de adquisición.

42 Vid. una amplia exposición en J. M. DE SOLAS RAFECAS, «La racionalización técnica de la contratación en el proyecto de Ley de Contratos del Sector Público», en RGDA núm. 14/2007, págs. 1-39). 
Los nuevos procedimientos son los tres siguientes (art. 178 LCSP):

a) Acuerdos marco.

b) Sistemas dinámicos de contratación.

c) Centrales de contratación.

A ellos debe añadirse la figura de las Juntas de Contratación, aunque se halle prevista en otro Libro (art. 291).

Por otra parte son procedimientos a aplicar no sólo por las Administraciones Públicas, que deberán someterse a lo dispuesto en la LCSP también en este caso, sino también por los demás poderes adjudicadores que no son Administraciones Públicas, aunque de nuevo dicha sujeción sea parcial, puesto que sólo alcanza a los contratos sujetos a regulación armonizada.

El art. 179 LCSP obliga a los demás entes del sector público que no sean Administraciones Públicas a ajustarse a las disposiciones del Título II del Libro III para los contratos sujetos a regulación armonizada, cuando acudan a los modos o procedimientos de adjudicación como acuerdos marco, sistemas dinámicos de adquisición o centrales de contratación.

\subsection{Acuerdos marco}

La definición de lo que son los acuerdos marco nos la ofrece la Directiva 2004/18/CE en su art. 1.5:

«Un «acuerdo marco» es un acuerdo entre uno o varios poderes adjudicadores y uno o varios operadores económicos, cuyo objeto consiste en establecer las condiciones que rijan los contratos que se vayan a adjudicar durante un período determinado, en particular las relativas a los precios y, en su caso, a las cantidades previstas» ${ }^{43}$.

La LCSP efectúa una regulación completa, dado que el TRLCAP contenía únicamente unas referencias muy limitadas a los acuerdos o contratos marco respecto del contrato de gestión de servicios públicos (art. 159 f)) o del contrato de suministros (art. 182. 1) y 183.1). La LCSP reitera la definición de la Directiva en su art. 180 añadiendo una advertencia: «que el recurso a estos instrumentos no se efectúe de forma abusiva o de modo que la competencia se vea obstaculizada, restringida o falseada». Y para ello establece dos límites generales:

a) Número mínimo de empresarios: deben ser tres (art. 180.2).

\footnotetext{
43 Un ejemplo de acuerdo marco puede verse en la Sentencia del TJCE de 29 de noviembre de 2007 (C-110/06), aunque en dicho caso la Sentencia declaró que el acuerdo marco era un contrato de servicios incluido dentro del ámbito de la Directiva de contratación pública, pero ésta no era aplicable porque la Comisión no demostró que dicho acuerdo marco superara el umbral comunitario por su cuantía.
} 


\section{SELECCIÓN DE CONTRATISTAS Y ADJUDICACIÓN DE CONTRATOS...}

b) Límite temporal: el contrato no podrá exceder de 4 años, salvo excepciones.

Seguidamente, la LCSP diferencia entre las dos fases de la licitación en los acuerdos marco:

1. $\left.{ }^{a}\right)$ La celebración del acuerdo marco (art. 181). Se regula principalmente la publicidad, de nuevo latiendo la diferencia entre contratos sujetos o no a regulación armonizada.

2.a) La celebración de contratos derivados del acuerdo marco (art. 182): Se impone, dado su carácter derivado del acuerdo marco, que estos contratos sólo puedan ser celebrados con las empresas que hayan sido originariamente partes del acuerdo marco, es decir, que hayan participado en la primera fase, en la licitación del acuerdo marco. A continuación se establecen diferentes reglas según el acuerdo marco se haya concluido con un único empresario o con varios.

\subsection{Sistemas dinámicos de contratación}

De nuevo para su definición cabe acudir a la Directiva 2004/18/CE:

«Un «sistema dinámico de adquisición» es un proceso de adquisición enteramente electrónico para compras de uso corriente, cuyas características generalmente disponibles en el mercado satisfacen las necesidades del poder adjudicador, limitado en el tiempo y abierto durante toda su duración a cualquier operador económico que cumpla los criterios de selección y haya presentado una oferta indicativa que se ajuste al pliego de condiciones» (art. 1.6).

El art. 183 LCSP reitera este concepto y añade la limitación temporal de este procedimiento a un plazo de 4 años, salvo excepciones.

La LCSP regula las diversas fases de este sistema de contratación:

1. ${ }^{a}$ ) Implementación (art. 184). Se trata de la imposición de reglas a los órganos de contratación para determinar la organización de este sistema de contratación que se va a desarrollar exclusivamente por medios electrónicos, informáticos y telemáticos. De nuevo aparece la categoría de los contratos sujetos o no a regulación armonizada a los efectos de publicidad, por la remisión que este precepto efectúa al art. 126.

2. ${ }^{a}$ ) Incorporación de empresas al sistema de contratación (art. 185). Se inicia con la presentación por el empresario de una oferta indicativa que puede ser admitida o rechazada, y que además puede ser mejorada en cualquier momento.

3. $\left.{ }^{a}\right)$ Adjudicación de contratos (art. 186). Rige el principio de que cada contrato debe ser objeto de una licitación específica. De nuevo se diferencia 
según los contratos estén sujetos o no a regulación armonizada, respecto de la publicidad previa del anuncio de licitación y posterior del resultado de la adjudicación. La adjudicación se efectuará a «la mejor oferta» (es la expresión que emplea el art. 186.4), que entiendo deberá ser la oferta económicamente más ventajosa según los criterios establecidos en el anuncio de licitación.

\subsection{Centrales de contratación}

También este modo de contratación, más que procedimiento de adjudicación, se toma de la Directiva 2004/18/CE que la regula en su art. 11, aunque ya se hallaba prevista en el TRLCAP (arts. 183 y 199 y disposición adicional 10. ${ }^{\text {a }}$ ). La Directiva las define en los siguientes términos:

«Una «central de compras» es un poder adjudicador que:

- adquiere suministros y/o servicios destinados a poderes adjudicadores, o

- adjudica contratos públicos o celebra acuerdos marco de obras, suministro o servicios destinados a poderes adjudicadores» (art. 1.10).

El art. 187 LCSP define este sistema de contratación en términos similares, aceptando que las centrales de contratación constituyen poderes adjudicadores, dado que «se sujetarán, en la adjudicación de los contratos y acuerdos marco que celebren, a las disposiciones de la presente Ley y sus normas de desarrollo» (apartado 3). En definitiva, la central de contratación de que se trate sustituye a las Administraciones Públicas y demás poderes adjudicadores, sustitución que le obliga a acomodarse a las normas previstas para éstos.

La LCSP diferencia entre dos supuestos:

a) Las centrales de contratación de ámbito autonómico o local. Se permite tanto su creación como centrales independientes (art. 188) como su adhesión a otras de ámbito estatal, autonómico o local (art. 189).

b) Las centrales de contratación de ámbito estatal. Para ellas se diferencia entre el régimen general (art. 190) como el régimen para la adquisición de equipos y sistemas informáticos (art. 191).

La disposición adicional 2. a $^{\circ}$ LCSP prevé reglas específicas para las centrales de contratación respecto de los municipios de población inferior a 5.000 habitantes. Fundamentalmente les ofrece la alternativa de llegar a acuerdos o bien de celebrar convenios de colaboración a tal efecto con las Diputaciones Provinciales o con las Comunidades Autónomas uniprovinciales ${ }^{44}$.

44 ORTEGa MONTORO manifiesta su posición favorable a estas vías de aprovechar los recursos provinciales por los pequeños municipios, lo que redundará en un ahorro de costes administrativos y económicos para 
Además «las sociedades y fundaciones y los restantes entes, organismos y entidades del sector público podrán adherirse a los sistemas de contratación centralizada establecidos por las Administraciones Públicas en la forma prevista en los apartados anteriores» (art. 189.3).

\subsection{Las Juntas de Contratación}

Constituyen, asimismo, un modo de contratación puesto que sustituyen al órgano de contratación. La LCSP las contempla en su art. 291.4 donde se afirma que se pueden constituir en el ámbito estatal Juntas de contratación «que actuarán como órganos de contratación, con los límites cuantitativos o referentes a las características de los contratos que determine el titular del departamento», en los que relaciona dicho precepto. Se sigue lo dispuesto en el art. $12.4 \mathrm{del}$ TRLCAP.

La D.A. 2. a 4 LCSP prevé la constitución de estas Juntas de Contratación en las entidades locales, en términos similares a los ya previstos en la disposición adicional 9. ${ }^{\text {. }} 2$ del TRLCAP, con la salvedad de la referencia expresa a la Junta de Gobierno Local en los municipios de gran población.

Las notas características de esta regulación son las siguientes:

a) Carácter potestativo de su constitución.

b) Delimitación de contratos en los que se puede acudir a esta figura.

c) Competencia del Pleno (Junta de Gobierno Local en los municipios de gran población) para acordar su constitución.

d) Miembros necesarios en la composición: Secretario (o asesor jurídico) e Interventor.

e) La actuación de la Junta de Contratación sustituye a la Mesa de contratación, por lo que se prescinde de su constitución.

éstos («La contratación de las Entidades Locales en la nueva Ley de Contratos del Sector Público 30/2007, de 30 de octubre: Sus especialidades», cit., págs. 32-33). 